\title{
GHERASIM LUCA - O POETICĂ SPECTACULARĂ
}

\author{
Andreea Mihaela Marinaș \\ Universitatea din București \\ Masteratul Studii literare, anul II \\ marinas_andreea_mihaela@yahoo.com
}

\begin{abstract}
The purpose of this paper is to analyse the spectacular features of Gherasim Luca's poetry. More specifically, the research starts from what generates the spectacular in his poetry: the erotica and the advertising feature of the poems. This study intends to analyse and explain how the eroticism of poetry, by its advertising dimension (meaning that poetry highlights the woman and erotic scenes like an advertising) offers to Gherasim Luca's poetry the spectacular dimension. The blend of the two areas (erotica and the conative function of language) creates the spectacular, transferring sexuality from intimacy to the public, just as an advertising highlights in public an element of intimacy. The research is based on some senses of eroticism, from the most important theoretical studies, as Georges Batailles, André Breton and Octavio Paz. Also, there are discussed the images of the woman and the sexual deviations in Gherasim Luca's poems.
\end{abstract}

Key-words: avant-garde, surrealism, erotic poetry, sexual deviations, conative function of poetry.

Motto: „La beauté convulsive sera érotique-voilée, explosante-fixe, magique-circonstancielle ou ne sera pas" (André Breton, Second manifeste du surrealisme)

Așa cum sugerează titlul, propun să identific și să analizez caracteristica spectaculară a poeticii lui Gherasim Luca, ceea ce generează spectaculosul în poezia lui și anume erotismul și caracterul publicitar al poeziei. Înainte de a motiva şi explica pe larg propunerea acestor două axe tematice, consider necesare amintirea câtorva date biografice (nu pentru că biografia explică bibliografia) și clarificări conceptuale ale avangardei și suprarealismului, ca formă de manifestare a avangardei, deși miza lucrării nu este de a analiza încadrarea poetului într-una din orientările avangardei istorice. Între sursele primare (manifestele avangardiste) şi cele teoretice despre avangardă, se găsesc câteva puncte de convergență și anume, remarcă Ion Pop: „refuzul convențiilor de orice fel, al autorității și « «odurilor de maniere») sociale și estetice, respingerea, în ultimă înstanță, a înseși consecințelor de literatură și artă, repudierea ierarhiilor constituite și, implicit, mefiența față de „recunoașterea oficială” a propriei valori, cultivarea

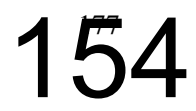


ostentativă a marginalității etc." " Gherasim Luca se identifică cu suprarealismul ca formă de manifestare a avangardei, formă care se împotrivește normelor sociale şi care vrea să abolească ipocrizia societății și caracterul ei normativ. Cum se încearcă asta? Prin găsirea unei „suprarealități” chiar ,în limitele acestei realităţi, a «miraculosului cotidian»"." Suprarealismul trebuie înțeles, ne spune același autor, ,ca o tentativă de a nu transcende realul, ci de a-l adânci”’3 sau ,,de a lua cunoștință cât mai netă și mai pasionată de lumea sensibilă" ${ }^{4}$ Poemele avangardiștilor se voiau a fi citite cu noi instrumente de lectură, pentru înțelegerea unei noi sensibilități, unei noi (anti)estetici care transgresează interesul tematic de la genaral la particular. ${ }^{5}$ In manifestul Dialectica dialecticii, Gherasim Luca și Dolfi Trost resping vehement trecutul literar în favoarea unui spirit permanent revoluţionar: „nici un moment istoria $\mathrm{n}$-a putut satisface relativul-absolut al tuturor dorințelor noastre." ${ }^{\prime 6}$ Ei mai afirmă că spiritul revoluţionar este consistent prin „magnetismul erotic”, fiind „,suportul insurecțional cel mai valabil”7 pentru menținerea acestei stări. Așa că violentarea imaginarului și a limbajului se face prin această forță a dorinței sexuale care abolește constrângerile sociale. Și totuşi, dincolo de discursul manifestelor avangardiste și suprarealiste, ,,e foarte puțin probabil ca ei să fi reuşit să dea, în linii mari, o imagine autentică a gândirii spontane, lăsată în totală libertate. Dimpotrivă, se pare că adesea ei nau provocat decât declanşarea unor mecanisme destul de superficiale, propagarea unui curent de gândire literară și mai totdeauna dirijată, în pofida dorinței autorului." ${ }^{8}$ Rămâne de analizat în ce măsură au reușit suprarealiștii să creeze spontaneitate în poezie, fără să ținem cont de un factor estetic, pentru că suprarealismul nu se vrea a fi un sistem de valori literare, de precepte sau de estetică literară, el doar ,transcrie experiențe interioare”. ${ }^{9}$ Prea puțini cercetători au cercetat latura spectaculară a avangardei, atât la nivel potenţial (ce generează spectaculosul în poezie), cât și concretizată prin puneri în scene

\footnotetext{
${ }^{1}$ Ion Pop, Avangarda în literatura română, București, Minerva, 1990, p. 6.

${ }^{2}$ Ovidiu Morar, Avatarurile suprarealismului românesc, București, Univers, 2003, p. 13.

${ }^{3}$ Ibidem, p.13.

${ }^{4}$ André Breton, What is Surrealism?, http://pers-www.wlv.ac.uk/ fa1871/whatsurr.html

${ }^{5} \mathrm{Cu}$ referire la împotrivirea față de adevărurile incontestabile (generale) printr-un ,flux dinamic al trăirii, spontaneitatea impulsurilor vitale, intuiția și imaginația, hazardul întâlnirilor revelatoare [...]", care sunt individuale. Vezi Ion Pop, Idem, p. 8

6 Gherasim Luca, D. Trost, „Dialectica dialecticii, Mesaj adresat mișcării suprarealiste internaționale", în Marin Mincu, Avangarda literară românească: [de la Urmuz la Paul Celan], st. introd., antologie și note bibliogr. de Marin Mincu, trad. textelor de Ștefania Mincu, Constanța, Pontica, 2006, p. 576.

${ }^{7}$ Ibidem, p. 576.

${ }^{8}$ M. Raymond, De la Baudelaire la suprarealism, trad. de L. Dimov, București, Univers, 1970, p. 351.

${ }^{9}$ Ion Pop, Avangardismul poetic românesc, București, Editura pentru Literatură, 1969, p. 242.
}

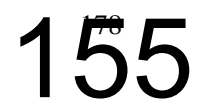


de film sau teatru. ${ }^{10}$

Poezia lui Gherasim Luca este un loc de întâlnire a unor dimensiuni care până atunci păreau inadecvate împreună în poezie: dragostea cu violența, brutalitatea cu publicitarul sau erotismul proiectat printr-un limbaj spot cu care să atragă receptorul. Avangardismul poetic al lui Gherasim Luca are și o funcție conativă (suplimentată și prin manifeste) în măsura în care, în termeni pragmatici, emițătorul presează receptorul, îl șochează, îl incită cu o mare forță impresivă, de unde și caracterul publicitar al limbajului său poetic. De aici și premisa lucrării: cum erotismul poeziei, prin dimensiunea lui publicitară (în sensul în care poezia scoate în evidență femeia și scenele erotice asemenea unei reclame) oferă poeticii lui Gherasim Luca doza de spectacular. Melanjul celor două arii creează spectaculosul, el transferând sexualitatea din intimitate în public, aşa cum și reclama scoate în public un element din intimitate. Obsesia erotică ar fi mai degrabă tratată nu ,,caricatural”, cum spune Ion Pop, ci publicitar. Poezia lui este una împotriva retorismelor, dar cu o ,,retorică a atitudinilor".11 Deși multe secvențe poetice sunt ,înscenări retorice și absurde", cu mult ,,prozaism voit" ${ }^{, 12}$, discursul este unul direct, incisiv, tăios. Ideea de spectacular e văzută şi de Ion Pop, dar fără să ilustreze pe larg caracterul spectacular al poeziei sale: ,gustul deja evidențiat pentru formulările spectaculoase prelungea înclinații mai vechi, fără teama de a cădea, uneori, într-o involuntară parodie, într-o clamoroasă utopie.",13

Pentru o minimă conceptualizare a erotismului, necesară în analiza acestei teme, consider utile două studii antropologice ale căror idei sunt concretizate în poezia lui Gherasim Luca. Primul este cel al lui Georges Bataille, care pornește de la o scurtă formulă a erotismului ca fiind ,,aprobarea vieții până și în moarte." Apropiindu-se (prea) puțin de poezie, autorul realizează o conexiune cu erotismul, spunând că ,ppoezia duce, în aceeaşi măsură ca oricare formă a erotismului, la indistincție, la confuzia obiectelor distincte. Ne duce la eternitate, ne duce la moarte." 14 Apoi, Octavio Paz, în Dubla flacără, afirmă că ,,relația erotică ideală implică, din partea libertinului, putere nelimitată asupra obiectului erotic, unită cu o indiferență la fel de

\footnotetext{
10 Vezi Paul Cernat, cap. „În căutarea unei noi estetici teatrale” și cap, „Mitologiile cinematografice ale integralismului” în Avangarda românească și complexul periferiei: primul val, București, Cartea Românească, 2007, pp. 269-292. Pornind de la constatarea unei noi perspective a avangardei asupra spectacolului și spectaculosului, autorul realizează un demers exegetic despre schimbările care s-au concretizat în aceste două arte prin influența avangardistă. Paul Cernat face o observație importantă în privința mutației de gust spectacular: „Încă din manifestul Poezia pe care vrem s-o facem, semnat de Geo Bogza, Gherasim Luca, Paul Păun și S. Perahim, extravaganța ludică se retrage în favoarea unei seriozități agresive: implicarea în social ia locul histrionismului cabotin și «iresponsabil». «(Petrecerea» estetică a anilor nebunatici se încheiase.” (p. 284).

${ }^{11}$ Ion Pop, Idem, p. 241.

${ }^{12}$ Ibidem, p. 241.

${ }^{13}$ Ibidem, p. 328.

${ }^{14}$ Georges Bataille, Erotismul, trad. de Dan Petrescu, București, Nemira, 2005, p. 36.
}

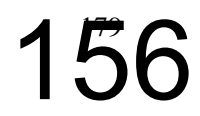


nelimitată față de soarta acestuia, iar din partea obiectului erotic, o supunere totală în faţa dorințelor și capriciilor stăpânului.",15

Revenind la ideea lui Bataille, conform căreia erotismul este asociat cu moartea și cu eternitatea, ca într-un univers palingenetic, de consumare, epuizare și reluare a actului erotic, femeia ca prezență erotică moare și renaște. În „Femeia Domenica d'Aguistti”, poem remarcant prin violența simbolică pusă în relație cu erotismul, eul se înfruptă din ,osul femeii moarte”, ține în gură „osul femeii care a murit/ și care trăiește numai în gura mea/ [...] Osul femeii moarte este pâinea mea de toate zilele" (GL 51-52) ${ }^{16}$. Aceeași complementaritate între sexualitate și moarte, care sunt „momentele acute dintr-o sărbătoare pe care natura o celebrează împreună cu mulțimea inepuizabilă a ființelor, ambele având sensul de irosire nelimitată", ${ }^{17}$ se regăsește și în proza lui Gherasim Luca. Deși pe aceasta nu am exploatat-o momentan în subiect, există numeroase pasaje, într-un limbaj neverosimil de tăios în care imaginarul erotic este violent și direct, asemenea unei reclame agresive. „Frumusețea convulsivă" ${ }^{\prime 18}$ de care vorbea Breton se regăsește și la Gherasim Luca, cu preponderență în proza „Inventatorul iubirii”, unde femeia este un mijloc de purificare, de negație a complexelor ereditare, un loc de refugiu: „În timp ce ochii se lasă atrași de o singură stea pe care nu știu de ce o fixez cu atâta fidelitate, mâinile mele subțiri, derutante, febrile, adevărate mâini de ucigaș, curăță coaja unui măr ca și cum aş jupui o femeie. $\mathrm{Cu}$ sexul în erecție, cu o sudoare rece pe tot corpul, respirând din ce în ce mai greu și mai repede, mușc mărul în timp ce privesc prin fereastră astrul depărtat cu o candoare de demon. [...] Iubesc această iubire inventată, această proiecție paradisiacă a creierului meu infernal, din care îmi hrănesc demonul. Proiectez la nesfârșit pe carnea ei îngerească convulsiunile, otrăvurile, furia, dar mai ales marea, teribila mea pasiune pentru sacrilegiu [... care] îmi întreține la o temperatură a negației și a negației negației toată ura mea nețărmurită pentru absolut tot ce există, pentru că tot ce există conține în virtualităţile lui subterane un mormânt pe care trebuie să-1 pângărim.” (GL 234) În acest pasaj din proza „Inventatorul iubirii”, se recurge la „gestul sfidător-iconoclast, de distrugere în efigie a conventiilor de ordin social și estetic."19, printr-o ,,ipostază spectacular-satanică". 20

\footnotetext{
${ }^{15}$ Octavio Paz, Dubla flacără: dragoste și erotism, trad. de Cornelia Rădulescu, București, Humanitas, 2003, p. 23.

${ }^{16}$ Citarea versurilor și prozei scurte a lui Gherasim Luca se realizează în corpul lucrării, din volumul Gherasim Luca, Inventatorul iubirii și alte scrieri, ed. de Ion Pop, Cluj-Napoca, Dacia, 2003.

${ }^{17}$ Georges Batailles, Idem, p. 73.

${ }^{18}$ André Breton, „Second manifeste du surrealisme”, scris în 1930. Vezi în vol. Manifestes du surrealisme, Gallimard, Paris, 1998, p. 87.

${ }^{19}$ Ion Pop, „Gherasim Luca, «inventatorul iubirii»”, în Tribuna, nr. 15/2013, p. 8.

${ }^{20}$ Ibidem, p. 8.
}

$$
157
$$


Potențialul spectacular se mai explică, de asemenea, și prin dinamismul care se opune staticului, prin spontaneitate, trăsătură a firii umane, nedobândită, ci înnăscută, de unde și întoarcerea la un nivel primar al sensibilității, spre senzații primare. Aceasta este și o explicație pentru asocierea erosului cu nivelul instinctual al omului care refuză normarea civilizatorie și care percepe femeia nu numai în forma cea mai concretă, ci mai mult decât atât, ca pe o suprarealitate din care eul mușcă, se înfruptă din ea ca din carne, ca dintr-o pradă. De pildă, în tot în poemul „Femeia Domenica d'Aguistti" se găsesc astfel de imagini spectaculoase, o combinație între canibalism și erotism: „Am în gură osul femeii moarte/ şi-1 muşc, și-l sug/ pentru că are puțină carne/ E dulce osul femeii și doare. / Dar câinii mahalalei - ucigașii - vor să-mi smulgă prada" (GL 51). Acest poem este comparabil, observă Petre Răileanu, cu Jurnalul de sex al lui Geo Bogza, ,prin violența imaginii.” Ceea ce îl face deosebit, observă același autor, este „« «dezordinea senzorială〉> într-o exprimare calculată ${ }^{\prime 21}$ : „Femeile care au păr pe piept/ femeile cu pumnul strâns/ femeile cu dinți în gură/ femeile care au dinți la unghii/ femeile care aleargă după mine au/ toți câinii între picioare/ femeile care îmi sparg capul cu lovituri de ciocan/ sunt femeile care îmi beau creierul/ și adună bucăţile creierului meu/ ca pe bucățile de pâine.” Aceeași comparație o făcuse și Ion Pop, dar subliniind o altă diferență: „E o poezie a obsesiilor erotice, înrudită cu cea a lui Geo Bogza din Jurnal de sex, dar lipsindu-i relieful plastic al aceleia". ${ }^{22}$ De fapt, poezia lui Gherasim Luca nu avea intenții plastice, miza mai degrabă pe agresivitatea limbajului, pe un limbaj rece, antipoetic. Și mai mult decât atât, textele au potențialul de a genera suprainterpretarea de pornografie ca acuză care i-a fost adusă de altfel lui Geo Bogza, texte care nu erau pornografie și nici atentat la bunele moravuri, ci, cum nota autorul, un atentat la liniștea și confortul spiritual al lumii." ${ }^{23}$ De asemenea, celebrul poem „Passionement”, pe care autorul îl citește spectaculos şi în filmul dedicat lui, prin bâlbâiala poetică poate fi apropiat de ideea revenirii la instinctual, o reîntoarcere chiar înainte de primele deprinderi de vorbire.

Tot în întoarcerea către nivelul primar al existenței și valorificând ideea lui Octavio Paz de la care am plecat, că „libertinul” este superior și în acelaşi timp indiferent față de obiectul erotic supus, apar asocieri şocante dintre elemente erotice și obiecte sau însuşiri. De exemplu, „femeia-pian, femeia-oglindă, femeia-țuică, femeia-primăvară" (GL 92) din poemul „Aceasta nu e decât o încercare” sau „buzunarul din stânga avea sexul femeii

\footnotetext{
${ }^{21}$ Petre Răileanu, Gherasim Luca, trad. din lb. franceză de Anișoara Biru, Iași, Junimea, 2005, p.43.

${ }^{22}$ Ion Pop, Avangardismul..., p. 238.

${ }^{23}$ Geo Bogza, ,Însemnări pentru un fals tratat de pornografie”, în Mircea Coloșenco (antolog.), Realism, pornografie și moralitate în artă, Iași, Timpul, 2008, p. 354.
}

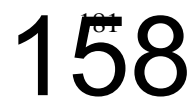


înghețate” (GL 74) în poemul „O serie de întâmplări cu urmări din ce în ce mai tragice" prin tehnica asocierilor arbitrare dintre obiecte incompatibilie şi ființe, așa cum propunea Breton în exigențele sale, imagini care tulbură privitorul (violentează privirea) și oferă elementul spectaculos, minunat sau „merveilleux", cum îl numea André Breton, pentru că se crează o suprarealitate prin transferul de însuşiri de la un obiect la altul. Mutilarea trupului după voința sau imaginația posesorului este interpretată de Ovid S. Crohmălniceanu ca un amestec de naturalism și suprarealism, pornind și de la porecla pe care i-o dăduseră prietenii poetului Gherasim Luca, Zóla: ,[poemele] își însușeau fără prejudecăți estetiste, tăietura reportajului crud"24: „bucăţica de femeie care-mi rămăsese pe unghie” (GL 74), din poemul „Oamenii nu au niciodată dreptate când îţi spun bună-seara”. Laitmotivul „câine” aproape că dobândește o dimensiune obsesivă și apare și în tematica erotică, semn al asocierilor tulburătoare și al instinctualităţii: „o femeie cu ciorapul întins pe pulpă se lasă linsă de un frate/ cu femeia asta m-am culcat și eu aseară/ -parola!/ -un câine! (GL 86). În acest poem din care am citat, ,Un oraș pe care îl voi părăsi mâine" (construit ca un dialog între eu şi spectatori), precum și în altele (exemplu: monologul adresat din „Cuvânt de deschidere la o expoziție de pictură") apare ideea de spectacol poetic în care se iau în derâdere publică oamenii și defectele lor: ,spectacolul cel mare e pe gratis/ [...] hei tu cucoană cu țîțele mai deschise ca la o panoramă" (GL 63). Există totuși, pe lângă toate aceste forme de reprezentare violentă a erosului la Gherasim Luca și rare secvențe estetice în care erotismul este îmblânzit: „Paravanele, pulpele ascund în gând/ strânsoarea bătăilor de mare/ și sunetul torsului plânge/ în adâncimi de pluș și cascade.” (Barbară 37) sau ,sexul tău era intact și cald și bun așa cum îl lăsasem" (GL 73).

Hazardul se amestecă cu fantasticul sau fantasmaticul și cu reveria erotică, reverie declanșată de ,,erosul transfigurator" ${ }^{25}$. Acest eros se regăsește şi la Gherasim Luca într-o formă ce va degenera în misticism demonic: „Florile otrăvite, aceste flori care pot fi vulturi sau degete sau cai marini și care sunt întotdeauna oglinzi sălbatice ieșite din noi, cu ochiul demonului reflectat în ele ca o amprentă, trec din sângele nostru în cel al femeii iubite, străbătând tenebrele. $O$ floră fantastică, virgină și dementă, imaginea fidelă a acestei faune înfricoșătoare din adâncul ființei noastre."26

Scena stridentă din „Sfânta Împărtăşanie” (GL 94) are detalii detabuizante, fiind un poem de amor cu o necunoscută, cu final revoltător, dacă nu deprimant: „,m-am plimbat prin dragoste și automobil,- dispăruse/ în locul ei rumega o babă zbârcită și cu ochelari care/ citea de zor pagini din

\footnotetext{
${ }^{24}$ Ovid. S. Crohmălniceanu, Evreii în mișcarea de avangardă românească, București, Hasefer, 2001, p. 150.

${ }^{25}$ Ion Pop, Idem, p. 321.

${ }^{26}$ Gherasim Luca, Vampirul pasiv, p. 87??
}

\section{9}


sfânta evanghelie.” Este un poem despre o femeie care abordează un necunoscut pe care îl aduce acasă, îi pune masa și apoi face dragoste cu el. Când se trezește cu gura plină de „o scârbă umedă” și este șocat de ceea ce îl atrăsese inițial.

$\mathrm{Cu}$ siguranță subiectul merită aprofundat în proza și în memoriile lui Gherasim Luca prin prisma unor interpretări freudiene, unde autorul se situează sub semnul lui Oedip. Cele cinci tentative de sinucidere sunt interpretate de Ovidiu Morar prin prisma ideilor freudiene. De exemplu, sinuciderea prin sufocare „,e considerată drept o formă veritabilă de negare a negației, întrucât subiectul se întoarce astfel la stadiul intrauterin, prenatal, în care nu există respirație, astfel încât efectul nașterii, angoasa - definit de Freud drept «(o strâmtoare a respirației» ca urmare a separației copilului de mamă $-\mathrm{e}$ eliminat." 27

În concluzie, am constatat că erotismul din poezia lui Gherasim Luca violentează peisajul literaturii române de avangardă, aproape sincronă cu cea europeană şi am analizat formele de reprezentare ale acestei teme: dorința, dragostea-fetiș încărcată de agresivitate și experiențele masochiste. Ideile poetice și cele din manifestele lui Gherasim Luca sunt în convergență cu programul propus de André Breton prin negația radicală şi accentele retorice: „Mi-am bătut în buze pionezele dinților/ și sânii tăi au răsunat zaruri pentru jocul târziu/ Și sângele parașută închisă/ și-a strigat imnul său în curcubeie."

\section{Bibliografie}

Bibliografie primară:

Gherasim Luca, Inventatorul iubirii și alte scrieri, ed. de Ion Pop, ClujNapoca, Dacia, 2003.

Gherasim Luca, Manuscrit facsimilé: Le vampire passif/ Vampirul pasiv, ed. de Petre Răileanu și Nicolae Tzone, București, Vinea, 2016.

Bibliografie secundară:

Georges Bataille, Erotismul, trad. de Dan Petrescu, București, Nemira, 2005. André Breton, Manifestes du surréalisme, Paris, Gallimard, 1985.

André Breton, What is Surrealism?, accesat în: http://perswww.wlv.ac.uk/ fa1871/whatsurr.html.

Paul Cernat, Avangarda românească și complexul periferiei: primul val, București, Cartea Românească, 2007.

Mircea Coloșenco (antolog), Realism, pornografie și moralitate în artă, Iași, Timpul, 2008.

${ }^{27}$ Ovidiu Morar, Avatarurile suprarealismului românesc, București, Univers, 2003, p. 206. Autorul aduce încă un argument etimologic pentru semnificația sufocării și anume „,termenul german Angst derică din adjectivul latinesc angustus, ce are sensul de strâmt, ingust.” De aici și originea și semnificația cuvântului ,,angoasă”. 
Ovid. S. Crohmălniceanu, Evreii în mișcarea de avangardă românească, București, Hasefer, 2001.

Marin Mincu, Avangarda literară românească: [de la Urmuz la Paul Celan], st. introd., antologie şi note bibliogr. de Marin Mincu, trad. textelor de Ștefania Mincu, Constanța, Pontica, 2006.

Ovidiu Morar, Avatarurile suprarealismului românesc, București, Univers, 2003

Octavio Paz, Dubla flacără: dragoste şi erotism, trad. de Cornelia Rădulescu, București, Humanitas, 2003.

Ion Pop, Avangarda în literatura română, București, Minerva, 1990.

Ion Pop, Avangardismul poetic românesc, București, Editura pentru Literatură, 1969.

Ion Pop, „Gherasim Luca, «inventatorul iubirii»”, în Tribuna, nr. 15/2013

Petre Răileanu, Gherasim Luca, trad. din lb. franceză de Anişoara Biru, Iaşi, Junimea, 2005. 